\title{
CORTICAL CLEANUP WITHOUT SIDE PORT IN SMALL INCISION CATARACT SURGERY
}

\author{
D. Udaya Kumar' ${ }^{1}$ G. Satyavathi², M. H. Khadari ${ }^{3}$
}

1 Professor, Department of Ophthalmology, Guntur Medical College, Guntur.

${ }^{2}$ Assistant Professor, Department of Ophthalmology, Guntur Medical College, Guntur.

${ }^{3}$ Assistant Professor, Department of Ophthalmology, Guntur Medical College, Guntur.

\section{ABSTRACT}

The aim of study was to achieve complete cortical cleanup and avoid problems related with sideport during Small Incision Cataract Surgery (SICS) so as to have a good visual out come with minimal recovery period, and a better quality of life. After nucleus delivery, cortical cleanup is an important step in any cataract surgical procedure. Cortex especially subincisional area (11 to 1 o'clock) is difficult to manage intraoperatively. Bimanual irrigation aspiration through two side ports, aspiration by J cannula, iris massage manoeuver, ice cream scoop manoeuver are various techniques of cortical matter aspiration. We acquired the technique of aspiration of subincisional cortex without using side port in all cases by paying attention on type of cataract, status of pupil, use of Adrenalin mixed BSS intraoperatively, Tunnel construction, Capsulorhexis size and capsular rim size at 12 o'clock.

\section{MATERIAL AND METHODS}

In this retrospective study of 1 year from 2013 to 2014, 60 patients (60 eyes) aged 40 years or older attending the General Ophthalmic Department were included in the study group with another group of 60 patients (60 eyes) as controls. The study was on age related cataracts which are basically. 1) Cortical cataract 2) Nuclear cataract 3) Subcapsular cataract. Proper assessment of cortical cataract based on its maturity such as a) Immature b) Mature c) Hyper mature and d) Morgagnian cataract, nucleus for its opalescence and color, size of posterior subcapsular opacity and pupillary status (Dilating well or not with mydriatics) were taken into consideration. Eyes with pseudoexfoliation having poor pupillary dilation were also included. Eyes with congenital anomalies, congenital cataract, gross corneal and retinal pathologies, and glaucoma were excluded.

\section{RESULTS}

Among 60 study eyes in the study group 35 presented with cortical, 20 with nuclear cataract and 5 with posterior subcapsular cataracts. In 58(96.6\%) cases, sideport was not required; 3(5\%) eyes had difficulty in aspiration of cortical matter at subincisional area of which 2 eyes (3.3\%) required side port. Intraoperative miosis was prevented $(100 \%)$ by Adrenalin mixed BSS in study group, but it was in $8(13 \%)$ eyes of controls. Postoperatively, minimal lens matter was seen in $1(1.6 \%)$ eye with no post-operative reaction or Posterior Capsular Opacification (PCO) at 6 months followup. Descemet's membrane separation was nil (100\%) in study group, which was seen in $8(13 \%)$ cases of controls at final followup of 6 months, which might be the cause for some postoperative discomfort in some patients in an otherwise normal eye.

\section{CONCLUSION}

Without side port cortical clean up in 360 degrees is possible in small incision cataract surgery by taking adequate measures. Use of side port may be limited to some selective cases of small pupil especially in those having exfoliation.

\section{KEYWORDS}

SICS, Side Port, Adrenalin Mixed BSS, Pseudoexfoliation(PFX), Capsulorhexis.

HOW TO CITE THIS ARTICLE: D. Udaya Kumar, G. Satyavathi, M.H. Khadari. "Cortical Cleanup without Side Port in Small Incision Cataract Surgery." Journal of Evolution of Medical and Dental Sciences 2015; Vol. 4, Issue 96, November 30; Page: 16181-16184, DOI: $10.14260 /$ jemds/2015/2376

\section{INTRODUCTION}

SICS is a good alternative to phaco-emulsification in countries where very high volume surgery with inexpensive instrument is required. It can be performed in dense cataract. While operating on cataract by SICS, most surgeons prefer to use side port for manoeuvers like Visco injection, capsulotomy procedures, and for subincisional cortex aspiration. The surgeon must be careful not to be aggressive during aspiration and irrigation of cortex, so as to avoid posterior capsule rupture or zonule rupture during these manoeuvers.

Financial or Other, Competing Interest: None.

Submission 19-11-2015, Peer Review 20-11-2015,

Acceptance 23-11-2015, Published 30-11-2015.

Corresponding Author:

Dr. G. Satyavathi,

12-22-17, Plot No. 6,

Sri Sainath Towers,

Post Office Road, Kothapeta,

Guntur.

E-mail: gsatyavathi1962@yahoo.com

DOI:10.14260/jemds/2015/2376
Proper preoperative grading of lens, pupil size and dilation, presence or absence of PXF avoides side port which has problems related to its entry, size, hydration at the end, post-operative leak, and deviation from normal anatomical continuity of some corneal layers such as Descemet's membrane separation, thereby disturbing endothelial cell function. The procedure minimizes surgical damage to cornea thereby maintaing structural and functional integrity of Descemets membrane and the endothelium and thereby the cornea postoperatively. Also it has low rate of complications.

\section{MATERIALS AND METHODS}

We studied a deries of 60 eyes in study group and another 60 in control group retrospectively for a period of about 1 year i.e. from February 2013 to January 2014 a series of 60 in study group and another 60 in control group to identify and avoid various problems related to side port in SICS. Patients included in the study were diagnosed as cataract. Above 40 years of age patients were recruited in the study. The study was approved by our Institutional Committe Board. Written and informed preoperative consent taken for all cases. The study was on age related cataract., ${ }^{1}$ which are basically. 1) 
Cortical cataract 2) Nuclear cataract 3) Subcapsular cataract. Pupillary examination to know the status of pupil (Dilating satisfactorily or not) was also included in the criteria. Eyes with Pseudoexfoliation (PXF) having poor pupillary dilation were also included. Eyes with congenital anomalies, congenital cataract were excluded. We excluded eyes having other ocular comorbidities such as gross corneal pathology, glaucoma, and retinal diseases. Visual acuity ranged from 6/36 to light perception and projection.

Several subjective and objective methods have been developed to assess cataract accurately both in vitro and in vivo. Smith et al. ${ }^{2}$ published their finding of a highly statistical significant relationship between opalescent quality and color of lens nucleus on the mechanical compression character of cataractous lens. As the opalescence and color increase, so does the hardness of the nucleus.

Preoperative classification of cataracts may aid planning of surgical approach to individual cataracts. Lens Opacity Classification System (LOCS) 111 grading rule., ${ }^{3}$ which is a subjective classification was followed while grading cataract. Cataracts were graded at slit lamp with respect to Nuclear Opalescence (NO standards are 1 to 6), Nuclear Color (NC standards are1 to 6), Cortical cataract (C standards are 1-6), and Posterior cataract (P standards are 1 to 5). A lens is classified as mature if there is no recognizable normal anatomic zones and hypermature if in addition there is swelling of lens.

Well-dilated pupil with a sharp red reflex enhances the ease of cataract extraction. As age progresses pupil may become miotic and dilates poorly. Not only senile miosis, senile exfoliation was also found to be a cause for poor pupillary dilation.

Among 60 study group we selected 35 cases of purely cortical, 20 cases of purely nuclear, another 5 cases of potsterior subcapsular cataracts. Control group also selected accordingly.

All surgeries were performed by one surgeon under peribulbar anaesthesia.

Preoperative data noted were age, gender, visual acuity, type of cataract slitlamp examination, IOP measurement, pupil reaction, fundus examination, B-scan and A-scan biometry, keratometry, and proper management of systemic diseases like diabetes, hypertension, asthma and cardiac evaluation by concerned specialists; $3: 2$ (F:M) was the gender ratio observed. Age group was more than 40 yrs.

All belong to poor socioeconomic status and most of them were farmers by occupation.

\begin{tabular}{|c|c|c|}
\hline Age Group & $\begin{array}{c}\text { No. of Patients in } \\
\text { Study Group }\end{array}$ & $\begin{array}{c}\text { No. of Patients in } \\
\text { Control Group }\end{array}$ \\
\hline $40-49$ & 19 & 15 \\
\hline $50-59$ & 34 & 36 \\
\hline More than 60 & 7 & 9 \\
\hline \multicolumn{3}{|c|}{ Table: 1 } \\
\hline
\end{tabular}

\section{Slit Lamp Observations}

Cornea and Anterior Chamber depth were normal except for Arcus senilis in most of the cases.

Iris color and pattern was normal except one case in study group and 2 cases in control group where it was thick and hyperpigmented.

Pupil - In all cases Pupils were Equal, Round, reacting normally to Light and Accommodation (PERLA); 6(10\%) in study group and $10(16.6 \%)$ in control group had small pupils and their dilatation with mydriatic was also poor. Cause of miosis was PXF in 4 out of 6 in study group and 6 out of 10 in control group. The etiology might be senile miosis for the remaining.

\begin{tabular}{|c|c|c|}
\hline Pupils Size & Study Group & Control Group \\
\hline Normal & 54 & 50 \\
\hline Small pupil due to & & 6 \\
\hline A) pseudoexfoliation & 4 & 4 \\
\hline B) senile miosis & 2 & \\
\hline \multicolumn{2}{|c|}{ Table: 2} \\
\hline
\end{tabular}

Lens - Cataracts were graded with respect to Cortical (C), Nuclear Opalescence (NO) Nuclear Color (NC) and Posterior subcapsular (P) (Table No. 3).

\begin{tabular}{|c|c|c|}
\hline Cataract Grade & Study & Control \\
\hline Cortical & 35 & 30 \\
\hline Nuclear & 20 & 22 \\
\hline $\begin{array}{c}\text { Posterior sub } \\
\text { capsular }\end{array}$ & 5 & 8 \\
\hline \multicolumn{2}{|c|}{ Table: 3} \\
\hline
\end{tabular}

\begin{tabular}{|c|c|c|}
\hline $\begin{array}{c}\text { Cataract } \\
\text { Maturity }\end{array}$ & Study & Control \\
\hline Immature & 27 & 30 \\
\hline Mature & 5 & 3 \\
\hline Hypermature & 3 & 2 \\
\hline \multicolumn{3}{|c|}{ Table: 4} \\
\hline
\end{tabular}

Visual Acuity ranged from Perception and Projection of light to 6/36 with BCVA. Fundus examination was within normal limits except for tessellation. B-scan performed in all cases.

Mydriatics produced good pupillary dilation in $90 \%$ (54 out of 60 ) cases in study group and 50 out of $60(83.3 \%)$ in controls. Pupil of size $6 \mathrm{~mm}$ or less than $6 \mathrm{~mm}$ was considered as abnormal.

\section{Preoperative Preparation}

The eye was prepared with systemic antibiotic along with topical and anti-inflammatory eye drops. IOP was kept under teens with oral Acetazolamide $250 \mathrm{mg}$ at night and $2 \mathrm{hrs}$. before surgery. Peribulbar block with infiltration of Xylocaine $2 \%$ combined with Bupivacaine 0.5\%, Adrenalin 1 in 200,000 and hyaluronidase as local adjuncts ${ }^{4}$ was given to achieve good anaesthesia.

\section{Incision and Surgical Strategies}

Adrenalin (Preservative free) mixed BSS was used to get needed Mydriasis. An external incision of $6-7 \mathrm{~mm}$ in cortical and nuclear cataract of grade 1 and 11 and $>7 \mathrm{~mm}$ in grade 111 and above was given $1.5 \mathrm{~mm}$ behind limbus. Tunnel was created. Internal incision given was about $8-9 \mathrm{~mm}$ and parallel to limbus. Caution was taken while creating and incising internal incision that it should not be more towards cornea which was important for aspiration of subincisional cortex. A good Continuous Curvilinear Capsulotomy. ${ }^{5}$ of size ranged from 6 to $6.5 \mathrm{~mm}$ achieved.

Efforts were made to keep the capsular rim near 12 o'clock position narrow; 2 to 3 relaxing cuts were given to capsular rim between 11 to 1 o'clock hours and at 7 o'clock in cases where there was big nucleus with inadequate pupillary dilation for easy prolapse of nucleus as well as for subincisional cortical aspiration. If capsular rim was wider than expected normal due to improper rhexis 1 to 2 radial cuts were given occasionally. Good hydrodissection tilted forward the pole of nucleus.

Measures were taken to reduce the size of nucleus by means of hydrodeliniation. Once equatorial edge of nucleus was out of bag, the whole nucleus was gradually rotated into anterior chamber by cartwheeling in a clockwise or anticlockwise fashion; under visco nucleus was delivered. 
Cortex aspirated totally with Simcoe irrigationaspiration cannula. In cases of poor mydriasis and in pseudoexfoliation (PXF) cases where corticocapsular adhesions were expected, cortical aspiration especially between 11 to 1 o'clocks was achieved by adequate visco, by placing tip of cannula below cortex, moving a little towards equator and gently rotating cannula tip to 45 to 180 degrees.

Gentle aspiration helds cortex tight at the tip of cannula. Moving cannula centripetally provides separation of 12 o'clock cortex easily. The above strategy was carried out in difficult cases of nuclear prolapse and for aspiration of cortex at 12 o'clock by the same surgeon. Perfect aspiration of cortical matter was then achieved. Tunnel closed after placing PC IOL.

\section{Intraoperative Difficulties}

\begin{tabular}{|c|c|c|}
\hline $\begin{array}{c}\text { Operative } \\
\text { Difficulties }\end{array}$ & No. In Study & $\begin{array}{c}\text { No. In } \\
\text { Controls }\end{array}$ \\
\hline $\begin{array}{c}\text { Soft globe making } \\
\text { side port difficult }\end{array}$ & --- & $2(3.3 \%)$ \\
\hline Sphincterotomy & $1(1.6 \%)$ & --- \\
\hline Nucleus prolapse & $2(3.3 \%)$ & $3(5 \%)$ \\
\hline Nucleus expression & $1(1.6 \%)$ & $2(3.3 \%)$ \\
\hline Conversion done & $1(1.6 \%)$ & $2(3.3 \%)$ \\
\hline $\begin{array}{c}\text { Intraoperative } \\
\text { miosis }\end{array}$ & $\begin{array}{c}\text { Adequate dilation } \\
\text { maintained }\end{array}$ & $8(13 \%)$ \\
\hline Cortical clean up & $3(5 \%)$ & $10(16.6 \%)$ \\
\hline $\begin{array}{c}\text { Descemet's } \\
\text { separation }\end{array}$ & --- & $12(20 \%)$ \\
\hline $\begin{array}{c}\text { Side port hydration } \\
\text { required }\end{array}$ & $2(3.3 \%)$ & $(100 \%)$ \\
\hline $\begin{array}{c}\text { Air bubble kept for } \\
\text { DM attachment }\end{array}$ & --- & $8(13 \%)$ \\
\hline \multicolumn{2}{|c|}{} \\
\hline \multicolumn{2}{|c|}{ Table: 5} \\
\hline
\end{tabular}

Difficulty felt while prolapsing nucleus in 2 cases of study and 3 cases of controls group where LS of grade 111 and above and pupil was $<6 \mathrm{~mm}$ with exfoliation. In these eyes pupil were stretched mechanically before capsulotomy and radial cuts were given to capsule. Sphincterotomy was done in rigid pupil when nucleus was of grade $1 \mathrm{v}$.

Nucleus Delivery: Conversion was done for $1(1.6 \%)$ case in study and for $2(3.3 \%)$ in control group, where inspite of capsulotomy with radial cuts to rim nucleus expression was difficult due to its big size. Conversion was done to prevent endothelial damage.

\section{Aspiration of Lens Matter}

Difficulty was felt in clearing lens matter at 12 o'clock in 03 cases in study group. All 3 cases had pupil size $<6 \mathrm{~mm}$ with pseudoexfoliation in 2 cases with sticky nature of cortical matter where chances of corticocapsular adhesions were more. Of those, 2 cases were managed by side port aspiration which was a little bit difficult task. Other case having minimal lens matter left over and followed for a period of 6 months.

Soft eye balls made difficult to give side port incision due to its low resistance in 2 cases in control group. There was difficulty in 10 cases during aspiration of cortical matter due to intraoperative pupil miosis in 8 cases while manoeuvering nucleus. In other 2 cases pre-operative pupillry pathology made aspiration difficult. Small side port size made cannula to enter into AC difficult, which made Descemet's separation in 8 cases. Air bubble was kept for approximation of $\mathrm{D}$. $\mathrm{M}$ at the end.

Tunnel closed by 10-0 nylon in cases where conversion was done.

\section{Post-Operative Complications}

Striate keratopathy was noted in $1(1.6 \%)$ case of study group, in which second attempt was made to remove nucleus. Postoperative visual acuity was $6 / 9$ to $6 / 6$ in all cases. No acive inflammatory reaction was observed. Round pupil was maintained in 58 cases. Pupil was irregular in $2(3.3 \%)$ cases due to intraoperative difficulty of nucleus prolapse.

In control group, air bubble in AC made postoperative examination of visual acuity and AC details difficult in 8 cases. Due to postoperative leak through side port one patiitnt was kept under observation for 2 days. Other complications seen were striate keratopathy in 2 cases, irregular pupil in 2 cases. Inspite of side port entry, retained lens matter observed in 2 cases where pupil was rigid and miotic which were managed by second operation.

However, the defect of side port remained for a long time in all cases under slit lamp examination; 4 cases in the study and 6 in control group developed PCO within 6 months of followup and were managed by Nd YAG capsulotomy; 6/9 to $6 / 6$ visual acuity could be achieved in all cases and in both the groups (Vide Table No. 6).

\begin{tabular}{|c|c|c|}
\hline $\begin{array}{c}\text { Postoperative } \\
\text { Observations }\end{array}$ & $\begin{array}{c}\text { No. In } \\
\text { Study }\end{array}$ & No. In Controls \\
\hline Striate keratopathy & $1(1.6 \%)$ & $2(3.3 \%)$ \\
\hline Air bubble in AC & --- & $8(13 \%)$ \\
\hline Irregular pupil & $2(3.3 \%)$ & $2(3.3 \%)$ \\
\hline Leak through side port & --- & $1(1.6 \%)$ \\
\hline Lens matter & $1(1.6 \%)$ & $2(3.3 \%)$ \\
\hline PCO & $4(6.6 \%)$ & $6(10 \%)$ \\
\hline Descemet's separation & --- & $8(13 \%)$ \\
\hline $\begin{array}{c}\text { postoperative visual } \\
\text { acuity }\end{array}$ & $\begin{array}{c}6 / 12 \text { to } 6 / 9 \\
(100 \%)\end{array}$ & $\begin{array}{c}\text { Cf } 4 \text { mts. to } 6 / 60 \\
\text { due to air } \\
\text { bubble) in } \\
8(13 \%)\end{array}$ \\
\hline on 1's pod & $\begin{array}{c}6 / 9-6 / 6 \\
(100 \%)\end{array}$ & $6 / 9-6 / 6(100 \%)$ \\
\hline Final VA at 6 wks. & \multicolumn{2}{|c|}{ Table: 6} \\
\hline \multicolumn{2}{|c|}{}
\end{tabular}

\section{RESULTS}

Cortical clean up was done in 58(95\%) cases without side port. Because of poor pupillary dilation ( 3 cases-5\%) and PXF (2 cases-3.3\%), there was intraoperative difficulty in subincisional cortex aspiration. In spite of additional care, one case $(1.6 \%)$ was left over post operative minimal retained lens matter which was followed regularly. There was no Descemet's Membrane separation (100\%).

Among control there was difficulty in cortex aspiration in $10(16.6 \%)$ cases, of which $8(13 \%)$ were due to intraoperative pupillary constriction at the time of manoeuvering nucleus and lens matter aspiration. Other $2(3.3 \%)$ cases had pupillary pathology of PXF, which made intraoperative cortical cleanup difficult. Lens matter was observed postoperatively in the above $2(3.3 \%)$ cases.

Descemet's separation was observed in $12(20 \%)$ cases. In all cases $(100 \%)$ side port hydration required at the end of surgery with $1(1.6 \%)$ Post operative leak. Visual acuity remained $<6 / 60$ in $8(13 \%)$ cases on first postoperative day because of air bubble in A.C. The final visual acuity at 6 weeks was $6 / 9$ to $6 / 6(100 \%)$ in both the groups. D.M remained separated in $8(13 \%)$ cases at the end of 6 months followup.

\section{DISCUSSION}

Manual small incision cataract surgery. ${ }^{6}$ offers similar advantages of phaco with the merits of wider applicability, better safety, a shorter learning curve and lower cost than phaco. The dimension of the wound depends upon the preoperative assessment of the nucleus size and the 
technique used to deliver the nucleus (Phaco sandwich or snare or pre-chopper will help reduce incision size).

Present methods of dealing cortical cleanup in SICS without side port, particularly at 12 o'clock have had limitations. Throughout procedure, good mydriasis is required. Tunnel width towards cornea need to be paid attention. The surgeon can simply ignore the tunnel corneal width, pupil size, capsular rim width and perform the manoeuvers of aspiration at 12 o'clock without side port, but this may result in inadvertant complications like zonular damage, vitreous disturbance, and retained lens matter at superior part thereby difficulty in placing posterior chamber IOL.

There may be Iris and pupillary damage at 12 o'clock thereby round pupillary contour is not maintained postoperatively. There will be post-operative corneal haze in upper part if manipulated excessively. Many surgeons have turned to devices like cannulas having specially designed tip which facilitate cortical cleanup at 12 o'clock without sideport. Successful cortical cleanup was achieved in all cases of cortical and posterior subcapsular cataracts with good intraoperative mydriasis. Cases having poor mydriasis were managed by proper intraoperative planning of radial cuts to capsule rim, maintaining thin rim width at upper part, and profuse use of viscoelastics.

Complications that occured intraoperatively in both groups such as nucleus prolapse and expression, conversion of tunnel, sphincterotomy were managed successfully. Variation in size of side port made tight entry of cannula that caused Descemet's separation. Hydration was required for all cases of SICS with side port. Large side port may lead to immediate post-operative leak that had happened in one case. Descemet's separation was more in conventional method. Variation in instrument sharpness was also another factor for separation of D.M. Moreover air bubble in A.C. for D.M. approximation made immediate post-operative observations like visual acuity, anterior chamber details difficult which made some patients apprehensive.

Separation remained for a long time and it leaves morphologic change in the area of side port of cornea. In mature and hypermature cataracts due to its slippery nature capsulotomy via side port may not always be uniform. We may need fine angled scissors to cut and complete rhexis via tunnel. Cases of very dense and brunescent. ${ }^{7}$ cataracts require large capsulorhexis to perform manouevers required to minimise complications.
Successful surgical outcome may be achieved by SICS without side port method. Our method does not appear to detract from surgical outcome

\section{CONCLUSION}

Our study concludes that without side port cortical clean up in 360 degrees is possible by taking adequate measures as mentioned. It minimizes operative steps like making side port, side port hydration, prevents Descemet's membrane separation, avoids air bubble in A.C. which prevents viewing of immediate post-operative A.C. details clearly and assessment of visual acuity. Good preoperative evaluation, proper intraoperative precautions, and timely judgement prevents both intraoperative and post-operative complications. The above study was compared with controls where intraoperative and post-operative difficulties were more. P.O. visual outcome was equally good.

The study concludes that side port is not mandatory in all SICS cases. Use of side port may be limited to some selective cases of small pupil especially having PXF, some hard cataracts and when intraoperative pupillary mydriasis not maintained. Due to its simplicity and low incidence of complications, the procedure is considered as alternative.

\section{REFERENCES}

1. Jack J Kasnski Brad Bowling, Clinical ophthalmology a systematic approach: 7 th edition, Chapter 9 , page270-271.

2. Alberts Jakobiecs Principles and practice of Ophthalmology, 3rd edition, Volume -1, Chapter 108, page: 1379.

3. Alberts Jakobiecs Principles and practice of Ophthalmology, 3rd edition, Volume -1, Chapter 108, page 1382-1385.

4. Alberts Jakobiecs Principles and practice of Ophthalmology, 3rd edition, Volume -1, Chapter 112, page 1421-1423.

5. Myron Yanoff \& Jays, Duker Ophthalmology, $3^{\text {rd }}$ edition, part 5, 5.4, page 428-429.

6. Jack J Ksnski Brad Bowling, Clinical ophthalmology a systematic approach: 7th edition, Chapter 9, page 285 .

7. American Academy of Ophthalmology, 2012-2013, BCSC, Section 11 Lens and Cataract, Chapter 10p 195-197. 